\title{
Mission Creep: An Analysis Of Accident And Emergency Room Activity In A Military Facility In Bosnia-Herzegovina
}

\author{
G Kenward, TNM Jain, K Nicholson
}

\begin{abstract}
Objective

To evaluate accident and emergency (A\&E) room activity at a Role 3 Multinational Integrated Medical Unit (R3 MIMU) facility in BosniaHerzegovina.

\section{Methods}

Retrospective analysis of all patients attending the $A \& E$ room from 1st October 1999 - 30th September 2002.

Results

1864 casualties are included in the analysis. $52.1 \%$ of casualties were Bosnian, $43.8 \%$ were military. Mean age of casualties was 35.5 years (SD 18.3), range 1 - 88 years. Traumatic injury was the leading cause of presentation (58.1\%). Following treatment $66.7 \%$ of all cases were discharged or returned to unit, with $19.8 \%$ admitted to a ward area. During the 3 year period there was a 5 fold increase in the number of Bosnian nationals treated, this included 80 children ( $<13$ years).

\section{Conclusion}

There has been a dramatic increase in

A\&E use during the period evaluated, particularly by the local population. The increasing number of locals treated, both adult and child, has the potential to undermine the R3 MIMU mission and increase dependency within the Bosnian population. A balance is needed to ensure the staff and functions of a hospital are maintained whilst preserving the capability to deal with an influx of military casualties.
\end{abstract}

Maj G Kenward MSc BSc(Hons) RGN QARANC

Acute Care Rotation Programme

Co-ordinator

Royal Centre for

Defence Medicine,

Selly Oak Hospital,

Birmingham, B29 6JD

Capt TNM Jain MSM

CD MD CCFP

Canadian Forces

Associate Staff

Physician of Emergency

Medicine

Quinte Health Care

Region,

Ontario, Canada

Capt K Nicholson MSc $\mathrm{BSc}$ (Hons) MBChB

RAMC

Senior House Officer Medicine, Frimley Park Hospital,

Camberley, Surrey,

GU16 5UJ
Key words: Bosnia, military, mission, clinical governance, humanitarian aid.

\section{Introduction}

An analysis of accident and emergency (A\&E) room activity was undertaken at a military Role 3 Multinational Integrated Medical Unit (R3 MIMU) located in Sipovo, Bosnia-Herzegovina in the United Kingdom area of responsibility. The hospital facility was initially established in 1995 following the Dayton Peace Accord and is staffed by British, Canadian, Dutch and Icelandic military personnel.

The mission of the R3 MIMU is to provide medical support to Multinational Division South West troops stationed in Bosnia in order to preserve the operational strength of NATO forces. Additionally, the R3 MIMU provides emergency treatment to any other casualties evacuated to its location. To achieve its mission statement R3 MIMU has 4 key tasks: to triage, resuscitate and stabilise casualties for transfer or return to unit; to provide life and limb saving surgery; provide the medical component for a helicopter Incident Response Team; and to provide diagnostic and specialist support to Role 1 medical assets. The hospital has capacity to receive two Priority 1 casualties (requiring immediate resuscitation), six Priority 2 casualties (requiring urgent resuscitation) and twelve Priority 3 casualties (walking wounded). In addition to managing military casualties the R3 MIMU offers the local population life, limb and eye saving treatment if aged 12 or over.

This paper discusses the type and trends of casualties treated within a military A\&E facility in Bosnia-Herzegovina over a 3-year period and considers the impact of treating local civilians on the hospital's ability to fulfil its mission statement.

\section{Methods}

Setting of study

A Role 3 military hospital with A\&E facility (consisting of one room with two treatment bays and equipment to manage two seriously injured casualties/medical emergencies as well as those with minor ailments), 2 operating theatres (one orthopaedic and one general surgical team), laboratory, X-ray department with digital capability and telemedicine, outpatient department, 10 bedded ward, 4 bedded intensive care unit, pharmacy, blood bank, physiotherapy department and mortuary. All casualties attending the hospital without prior appointment were screened by $\mathrm{A} \& \mathrm{E}$ staff and treated or referred.

Patients and data collection

The attendance $\log$ for all casualties presenting to the A\&E of R3 MIMU between 1st October 1999 and 30th September 2002 was reviewed. Documented information included demographics, reason for attendance and disposal. Data was coded, entered into an excel database and then transposed into a statistical package.

Statistical analysis

The Statistical Package for Social Sciences version 10.0 was used for data analysis. Students' t-test was used to compare inter- 
group means and a ' $p$ ' value of 0.05 was considered statistically significant. Proportions were compared using $z$-test or odds ratio (OR) and its 95\% confidence interval (CI) calculated (1).

Study limitations

There was reliance on retrospective records where documentation was occasionally incomplete.

\section{Results}

Demographics

1875 casualties were identified from attendance records. 11 cases were excluded, as demographic detail was absent. 1864 casualties were included in the analysis. $81.1 \%$ were male. The average age for all patients was 35.5 years (SD 18.3), range 1 88 years. 80 children under 13 years of age attended $\mathrm{A} \& \mathrm{E}$ over the 3-year period. $43.8 \%$ $(35 / 80)$ of these were 6 years of age or younger.

$52.1 \%$ of patients were Bosnian and $43.8 \%$ were SFOR (Stabilisation Force) personnel. A further breakdown is given at Table 1. Bosnian national patients were significantly older than SFOR personnel ( $t-$ test, $\mathrm{p}=0.001$, mean difference of 12.1 years, 95\% CI 10.1 - 14.1).

Events leading to presentation

Traumatic injury was the leading cause of presentation to A\&E (58.1\%, 1082/1864).
The cause of traumatic injury was poorly documented, but included road traffic accidents (RTAs) (9.4\%), falls (3.7\%), gun shot wounds $(0.9 \%)$ and mine blast injuries $(0.4 \%)$ (Table 1). Non-trauma related conditions accounted for $41.9 \%$ of attendances and included the spectrum of medical and surgical conditions.

Types of injury sustained

The commonest injuries seen were soft tissue injuries $(47.0 \%)$ and fractures $(27.7 \%)$ (Table 2). Fractures were further classified as single bone $(72.5 \%)$, multiple (2 or more bones: $7.6 \%$ ), dislocation $(10.3 \%)$, crush $(6.0 \%)$ or amputation $(3.6 \%)$.

Disposal following treatment

The commonest disposal following treatment in A\&E was discharge $(67.6 \%$ of cases). $19.8 \%$ of casualties were admitted to ward. Military personnel were twice as likely to be admitted following treatment than Bosnian nationals $(\mathrm{OR}=2.21 ; 95 \%$ CI 1.76 2.76). $7.3 \%$ of casualties were transferred to another medical facility. Bosnian nationals were almost eight times more likely to be transferred to another facility, be it to the local clinic or to a higher level of care (OR=7.61; 95\% CI $4.33-13.39) .3 .6 \%$ of casualties proceeded to the operating theatre from A\&E. Only $0.5 \% \quad(10 / 1864)$ of casualties died whilst in A\&E. A breakdown of disposal by nationality is at Table 3 .

Table 1. Demographics and injury cause over 3-years. *The category 'other' includes Czech servicemen, UK based civilians and non-military visitors such as non-government organization staff.

\begin{tabular}{|c|c|c|c|c|c|}
\hline \multirow[t]{2}{*}{ Demographics } & Bosnian & UK & Canadian & Dutch & Other $\star$ \\
\hline & $\mathbf{n}=971$ & $\mathrm{n}=525$ & $\mathrm{~N}=168$ & $\mathrm{n}=124$ & $n=76$ \\
\hline Male & 705 & 477 & 152 & 108 & 70 \\
\hline Female & 266 & 48 & 16 & 16 & 6 \\
\hline Age mean (SD) & $40.6(22.1)$ & $27.6(7.2)$ & $31.0(7.9)$ & $28.5(8.9)$ & $33.2(8.8)$ \\
\hline Age range & $1-88$ & $18-52$ & $18-56$ & $17-53$ & $19-54$ \\
\hline \multicolumn{6}{|l|}{ Cause of visit } \\
\hline RTAs & $45(4.6 \%)$ & $23(4.4 \%)$ & $19(11 \%)$ & $13(10.5 \%)$ & $2(2.6 \%)$ \\
\hline Falls & $25(2.6 \%)$ & $11(2.0 \%)$ & $3(1.8 \%)$ & $0(0)$ & $1(1.3 \%)$ \\
\hline GSW & $5(0.5 \%)$ & $0(0 \%)$ & $3(1.8 \%)$ & $1(0.8 \%)$ & $1(1.3 \%)$ \\
\hline Blast & $2(0.2 \%)$ & $1(1.8 \%)$ & $0(0 \%)$ & $0(0 \%)$ & $1(1.3 \%)$ \\
\hline Unknown injury cause & $468(48 \%)$ & $302(58 \%)$ & $77(46 \%)$ & $56(45 \%)$ & $28(37 \%)$ \\
\hline Non-trauma & $429(44 \%)$ & $190(36 \%)$ & $66(39 \%)$ & $54(44 \%)$ & $43(57 \%)$ \\
\hline
\end{tabular}

Table 2. Common injuries sustained. (Some patients had multiple injuries and less common injuries are not listed).

\begin{tabular}{|l|l|l|l|l|l|}
\hline Commonest injuries & Bosnian & UK & Canadian & Dutch \\
$\mathbf{n = 1 0 8 2}$ & $\mathbf{n = 5 4 2}$ & $\mathbf{n = 1 0 2}$ & $\mathbf{n = 7 0}$ & $\begin{array}{l}\text { Other } \\
\mathbf{n = 3 3}\end{array}$ \\
\hline Soft tissue & $177(18.2 \%)$ & $199(37.9 \%)$ & $69(41.0 \%)$ & $47(37.9 \%)$ & $18(23.7 \%)$ \\
\hline Fractures & $189(19.5 \%)$ & $56(10.7 \%)$ & $23(13.7 \%)$ & $17(13.7 \%)$ & $16(21 \%)$ \\
\hline Lacerations & $118(12.1 \%)$ & $44(8.4 \%)$ & $2(1.2 \%)$ & $1(0.8 \%)$ & $5(6.6 \%)$ \\
\hline Head injury & $34(3.5 \%)$ & $19(3.6 \%)$ & $2(2.9 \%)$ & $5(12.1 \%)$ & 0 \\
\hline
\end{tabular}


Table 3. Outcomes. (Outcome data missing for 60 casualties).

\begin{tabular}{|l|l|l|l|l|l|}
\hline \multirow{2}{*}{ Outcome } & Bosnian & UK & Canadian & Dutch & Other \\
\cline { 2 - 6 } & $\mathbf{N = 9 7 1}$ & $\mathbf{n = 5 2 5}$ & $\mathbf{n = 1 6 8}$ & $\mathbf{n = 1 2 4}$ & $\mathbf{n = 7 6}$ \\
\hline RTU & $648(66.7 \%)$ & $340(64.8 \%)$ & $97(57.7 \%)$ & $80(64.5 \%)$ & $55(72.4 \%)$ \\
\hline Admit ward & $117(12.1 \%)$ & $144(27.4 \%)$ & $45(26.8 \%)$ & $35(28.2 \%)$ & $14(18.4 \%)$ \\
\hline Admit ITU & $14(1.4 \%)$ & $1(0.2 \%)$ & $3(1.8 \%)$ & $1(0.8 \%)$ & $1(1.3 \%)$ \\
\hline Theatre & $38(3.9 \%)$ & $12(2.3 \%)$ & $10(5.9 \%)$ & $4(3.2 \%)$ & $2(2.6 \%)$ \\
\hline Transfer & $119(12.3 \%)$ & $10(1.9 \%)$ & $3(1.8 \%)$ & 0 & $1(1.3 \%)$ \\
\hline Death & $8(0.8 \%)$ & 0 & 0 & 0 & $2(2.6 \%)$ \\
\hline
\end{tabular}

\section{Discussion}

The discussion briefly considers the study findings in comparison with previous studies before debating the impact of treating increasing numbers of Bosnian nationals on the hospitals mission statement.

Traumatic injury was the leading cause of presentation to $A \& E$ in all groups of patients. Between nationalities UK SFOR (stabilisation force) had the highest incidence of traumatic injury (64\%). This figure appears much higher than previously reported. Sanchez (2) found traumatic injury accounted for only $28 \%$ of visits to a United States medical facility in Bosnia-Herzegovina in 1996. However, Sanchez did not define causes for $33 \%$ of hospital visits, potentially bringing their injury rate up to a comparable $61 \%$. Other factors may also contribute to the difference in trauma related presentations, including role change and the increasing sporting activity of soldiers as Bosnia stabilised. This hypothesis is supported by the findings of Clasper et al (3) who in an analysis of orthopaedic injuries sustained by soldiers in Bosnia found sports injuries to be the leading cause of morbidity.

Proportionally more fractures and lacerations were seen amongst Bosnian nationals than military casualties. The limited availability of X-ray and resources at the Bosnian clinic is believed a contributory factor; their X-ray department was only staffed for 6 hours a day 5 days a week. This resulted in many out-of-hour referrals with suspected fractures to R3 MIMU. The net result of these referrals was an increased workload for on-call staff, particularly the radiology and laboratory technician who each had sole responsibility to provide $24 / 7$ cover for the duration of a three month tour. The impact of this additional workload was not assessed but may impede operational effectiveness.

The leading cause of admission to a hospital bed for all groups of casualties was traumatic injury (43\%, Table 3), slightly less than found by Croft (4) in a review of hospitalisations in Split in 1996 (48\%). The types of trauma resulting in admission were predominantly fractures, soft tissue injuries and larger lacerations. As might be expected, military personnel were more likely to be admitted following treatment than Bosnian nationals. Such an admission pattern is as expected and R3 MIMU policy recommends that no more than three Bosnian nationals should be admitted to the 10-bedded ward area at any one time to ensure capacity to treat an unexpected surge of military personnel. Additionally, there is a lower threshold for admission of military personnel who might otherwise return to the barrack room.

Over the study period a dramatic increase in the activity levels of the A\&E facility were noted (Chart 1), from 197 casualties in the first year to 1027 in the third. The pattern of injuries also changed, with more GSW, blast injuries and multiple fractures seen in 1999 compared to 2002. The type of conditions seen in 2002 is more representative of those seen across the spectrum of treatment areas in an accident and emergency department in the UK or Canada; predominantly minor injuries with the occasional cardiac arrest or major trauma. The increase in SFOR casualty numbers, but for less serious conditions, suggests an inclination to accept more minor conditions by the clinicians staffing A\&E, rather than an increase in SFOR numbers. The same theory may hold true for the dramatic increase in Bosnian nationals treated by $\mathrm{A} \& \mathrm{E}$.

Chart 1. A\&EE attendance by year. (No missing data).

RESUS attendence by year \& nationality

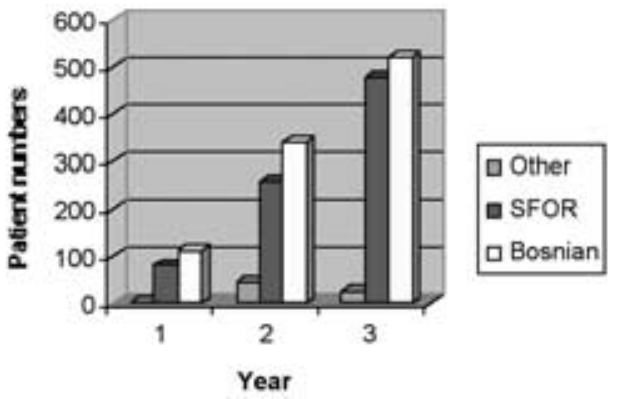

Bosnian nationals, numbering some 13,000 in the Sipovo area, were the greatest users of R3 MIMU (52\%) despite having a medical facility in the town centre offering a 24-hour service, albeit with limited X-ray capability. Medical assistance provided to the local community by R3 MIMU is generally well received and does much for Bosnian/ 
military relations. However, the impact of the assistance on the wider Bosnian population is debatable. Rubin et al (5) suggests that ad hoc contributions to local medical welfare may be less effective than perceived. Furthermore, current military doctrine in Bosnia-Herzegovina aims to promote selfsufficiency rather than dependency.

Competing with the aim of reducing Bosnian dependency is the need to maintain the skill levels of clinicians and a functioning hospital. However, there would appear to be a fine balance between maintaining clinical readiness and withholding capacity to manage unforeseen casualty surges, which are rare but do occur. For example, a Czech Hip helicopter crashed in Bos Krupa, northwest Bosnia in January 1998, resulting in seventeen casualties being airlifted to the then British Hospital Squadron, Sipovo (6). This example highlights the importance of maintaining treatment capacity within the military medical system.

Despite a policy not to treat those aged under 13 years, the number of children seen within the A\&E facility increased proportionally with overall activity levels. Of 80 children treated over the 3 year period 48 were seen in the last year. The majority of children presented following traumatic injury $(68 \%)$ resulting in fractures, lacerations and soft tissue injury. Non-traumatic conditions included seizures, acute abdominal pain and primary care problems.

The increase in children treated is not reflected by a change in demographics of the local population or in the type of medical facilities available locally. It is presumed that the increase in numbers results from a change in practice by those working within the R3 MIMU. A consequence of the increased number of children accepted for treatment is that more children were transferred for further care and more required admission to the ward or intensive care area. The admission of children to an adult facility has clinical governance implications as the preparedness of staff to deal with paediatric emergencies and continued care may vary. Whilst it is difficult to refuse treatment to sick children, many of the children treated did not have life or limb threatening conditions. There is currently no mandate to provide paediatric trained doctors or nurses for military operations in Bosnia, and unlikely to be in the near future. Treating sick children may, therefore, place an unacceptable burden of risk on the staff involved and fail to provide the best service. The impact on children of being nursed in an adult ward and for soldiers nursed next to them is uncertain and beyond the scope of this paper, but is clearly of concern. A more appropriate strategy may require an aggressive enforcement of the 'life or limb' treatment philosophy for children, and indeed local adults, with more emphasis on treat and transfer to Bosnian run medical facilities. Despite this recommendation, the number of children presenting clearly justifies a requirement to have a paediatric treatment capability, a requirement that has been previously identified during an operational deployment to Kosovo (7) and more recently in Iraq.

\section{Conclusion}

This analysis of Role 3 A\&E room activity has identified a number of important issues. Firstly, it has demonstrated that better and more accurate record keeping is required. A standard format, accessible by all nations would provide a more accurate picture of A\&E activity.

The dramatic increase in the number of children treated, despite R3 MIMU policy, is of concern. The authors feel that regardless of the mission or hospital policy, children will present for treatment, often in a critical condition. Therefore, appropriately trained staff with equipment to manage paediatric emergencies should be part of NATO health facilities if located near a civilian population. Emergency paediatric equipment was delivered to R3 MIMU during the latter part of this study.

This study suggests that 'mission creep' is highly probable, and likely to increase with the duration of a medical deployment. The increasing use of the R3 MIMU to treat locals has potential to compromise the hospital mission by limiting access for military personnel. It may also feed a dependency culture that could leave a void in local medical care provision when NATO departs. Although most military medical facilities have policies in place to limit the treatment of civilians, the interpretation of policy is varied. Clear policy, objectively enforced, will ease the decision making process and help ensure that military Role 3 facilities are operationally prepared.

\section{References}

1. Altman D. Practical Statistics for Medical Research, London, Chapman and Hall, 1991.

2. Sanchez JL, Craig SC, Kohlhase K, Polyak C, Ludwig SL, Rumm PD: Health assessment of US military personnel deployed to Bosnia-Herzegovina for Operation Joint Endeavor, Mil Med 2001; 166: 470-474.

3. Clasper JC. The dangers of sport on an operational deployment, f R Army Med Corps 2001; 147: 297300.

4. Croft AM, Hoad NA, Dale RF. Hospitalisation of British troops during operation Joint Endeavor (Bosnia), Mil Med 1999; 164: 460-465.

5. Rubin M, Heuvelmans JH, Tomic-Cica A, Birnbaum ML. Health-related relief in the former Yugoslavia: needs, demands, and supplies, Prehosp Disaster Med 2000; 15:1-11.

6. Vassallo DJ, Sargeant ID, Sadler PJ, Barraclough CJ, Bhatt BM, Wilco AC. Mass casualty incident at Hospital Squadron Sipovo, Bosnia following a Czech hip helicopter crash, 8 Jan 1998, f R Army Med Corps 1998; 144: 61-66.

7. Hodgetts TJ, Kenward G, Masud S. Lessons from the first deployment of emergency medicine, $\mathcal{F} R$ Army Med Corps 2000; 146: 134-142. 